\title{
Halogens in deep Earth carbonates
}

\author{
YING-JUI HSU' ${ }^{1}$, XIAOLEI FENG ${ }^{2,3}$, SIMON A. T. REDFERN $^{1}$
}

${ }^{1}$ Asian School of the Environment, Nanyang Technological

University; yingjui.hsu@ntu.edu.sg

; simon.redfern@ntu.edu.sg

${ }^{2}$ Department of Earth Sciences, University of Cambridge; xf232@cam.ac.uk

${ }^{3}$ Center for High Pressure Science and Technology Advanced

Research, Beijing 100094, China

Halogens subducted from Earth's surface to the mantle play an important role on many geochemical processes including element recycling in deep Earth. The occurrence of various hydrated sediments, altered oceanic crust, and abyssal serpentinites has been widely recognized for their potential role in transferring halogens from Earth's surface to the deep mantle. The abundance of halogens, in particular fluorine, is found to be exceptionally high in carbonatite melt. They have a major role on the degree of partial melting and volatile saturation as a function of pressure and temperature. However, the origin and source of halogens stored in the deep Earth remain uncertain.

Calcium carbonate $\left(\mathrm{CaCO}_{3}\right)$ remains stable at elevated pressure, and plays a key role in the deep carbon cycle. Here, we report how halogens may be incorporated into the various phases of $\mathrm{CaCO}_{3}$, affecting their relative stability under pressure. Three common polymorphs of $\mathrm{CaCO}_{3}$ (calcite, aragonite, and vaterite) are considered. Periodic models of fluorine-bearing $\mathrm{CaCO}_{3}$ have been built for strucural optimization, and different substitution mechanisms are introduced to predict the stability of F-, Cl- and $\mathrm{Br}$-bearing $\mathrm{CaCO}_{3}$ polymorphs at elevated pressure. Based on our firstprinciples calcualtions of the structrual changes of $\mathrm{CaCO}_{3}$ polymorphs with pressure and halogen substitution, our results show that fluorine is stabilized in $\mathrm{CaCO}_{3}$ by pressure. This finding may indicate that subducted marine carbonates are a potential reservoir for halogens, including $\mathrm{F}, \mathrm{Cl}$ and $\mathrm{Br}$, at depth, and may be key in explaining the fluorine depletion of the oceans and enrichment of the mantle. 